\title{
Impact of environmental noise on insects' physiology and ethology - A study on ants as models
}

\author{
Marie-Claire Cammaerts ${ }^{1 *}$ and David Cammaerts ${ }^{2}$ \\ ${ }^{1}$ Independent Researcher (Rtd.), Biology of Organisms Department, University of Brussels, Belgium \\ ${ }^{2}$ Independent researcher, 13, Rue Silvela, 4900, Spa, Belgium
}

\begin{abstract}
Noise is one of the environmental factors which can impact insects' physiology and ethology. In the present work, we examined the effects of two kinds of noise: beats (42 and 200 beats per minute) and flowing water noise (a natural environmental sound) on ants' (used as insect model) locomotion, orientation, audacity, tactile perception, brood caring behavior, aggressiveness against nestmates and against aliens, escaping behavior, cognition and short-term memory. We found that 42 and 200 BPM increased the ants' sinuosity of movement, decreased their orientation capability, audacity, tactile perception, brood caring behavior, escaping ability, cognition and short-term memory, and induced slight aggressiveness against nestmates. On the contrary, flowing water noise did not affect the above cited physiological and ethological traits, and even somewhat enhanced some ones. Each experiment being short lasting, the impact of the experimentally added noise very quickly vanished after the noise was stopped. Nevertheless, it can be concluded that brutal, choppy noise adversely affects ants' (and probably other organisms') health (at least their physiology and ethology), and should thus be avoided in their vicinity, and that smooth calming noise has a beneficial impact on them, reducing stress and improving social relationship as well as cognition and memory for instance.
\end{abstract}

\section{Introduction}

It is well-known that numerous environmental parameters, including those created by humans, influence the organisms' physiology, behavior and general health [1]. These environmental parameters are, for instance, the food availability and consumption rates, the temperature, the humidity, the light, presence and concentrations of chemical compounds, magnetic and electrical field, presence of predators, population density, etc.... Sound is one of those factors that can influence the physiology and/or the behavior of organisms, including humans [2].

A very large number of organisms rely on sounds, i.e. on acoustic vibrations perceptible or not by humans, for performing a large variety of behaviors. For instance, such vibrations are known to be used for communicating and mating in numerous insects, fishes, amphibians, birds, and mammals [3]. As the environment baseline level of vibrations could be greatly increased in anthropogenicaly disturbed environments, there is growing concerns about the effects of those "artificial" vibrations/sounds on animals' (including insects') and plants' physiology and ethology [4-12]. Very recently, Barton and coauthors [13] have studied experimentally the effect of noise pollution on a model ecosystem, showing negative effects of noise pollution through trophic cascades.

In anthropogenicaly modified environment, ants play major roles as predators and can even "shape" the trophic structure of the local communities [14]. Considering how much ants relies on vibrations for performing major social behaviors [15], we can express some concerns about the potential effects of noise pollution, i.e. artificial high levels of vibrations, on ant's physiology and/or behavior, eventually leading to some cascades of negative effects.

The present study, i.e. examining the influence of two kinds of noise on ants used as insect models, has thus two aims: providing some insight on potential harmful effects of artificial sounds on ants, and exploring the idea of using ants as organism model to investigate effects of noise pollution on humans, as both organisms are sensitive to vibrations.

The two kinds of used noise were, firstly, a brutal one, beats, and secondly a smooth one, flowing water noise. The controls were the ants' physiological and ethological traits assessed without any artificial noise (only baseline noise, considered as nearly constant). Here below, before relating our methods and results, we explain why we experimented on ants, which species we used and what we know on it, and we cite the different physiological and ethological traits we examined.

\section{Why using ants as models?}

Most non-human animals' and humans' physiological and ethological traits are fundamentally similar [16]. They are often firstly examined on animals as models (e.g. fruit flies, cockroaches, bees, mice, monkeys), and then studied on humans [17]. Insects are often used as model organisms due to their rapid development and easy maintenance in laboratory [18]. Hymenoptera, among others, are used [19]. Ants could advantageously be so [20]. Indeed, these social insects present, among others, colonial regulation, labor division and information exchange thanks to tactile and chemical signals (pheromones) $[15,21,22]$. They construct sophisticated nests, care of their brood, and chemically mark the different parts of their habitat [21]. They navigate, recruit congeners, relocate their nest, clean its

${ }^{\star}$ Correspondence to: Marie-Claire Cammaerts, 27, square du Castel Fleuri, 1170, Bruxelles, Belgium, E-mail: mccammaerts@gmail.com

Key words: cognition, locomotion, memory, Myrmica sabuleti, polution, social relationship

Received: September 22, 2018; Accepted: October 04, 2018; Published: October 08,2018 
inside and create cemeteries [15]. According to such a complex biology/ behavior, they could serve as biological models for various studies. The impact of stressors or environmental changes could be examined on them, and hypothesis of effects of these stressors on other organisms can be emitted.

\section{Which species was used?}

We intensely studied the ants of the genus Myrmica, looking, among others, to their ecology, eyes morphology, angle of vision, visual perception, recruitment strategy, navigation system, learning [23], and to the ontogenesis of some of their abilities [24]. The study of the effect of electromagnetic fields (EMF) on their learning, memory capabilities and responses to pheromones showed that they could be used as biological models $[25,26]$. Effectively, they were so while we examined on them the potential harmful impact of products used by humans [27-30]. Effects recorded in humans were also observed in ants with good similarities in the nature of those effects, and other harmful effects, from which humans may potentially suffer, were recorded in these studies. In the present work, we used again the ant M. sabuleti Meinert 1861 as insect models for studying the consequences, on physiological and ethological traits, of added environmental noise, to investigate the effects of noise pollution on insects, and to evaluate the potential physiological and behavioral impact of noise pollution on human beings.

\section{Which traits were examined?}

We examined 11 traits on ants living under normal conditions, then on these ants living with added noise. These traits were: speed of locomotion, sinuosity of movement, orientation ability, audacity, tactile (pain) perception, brood caring, aggressiveness towards nestmates, and aggressiveness against aliens, escaping ability, cognition, and memory. The simple, rigorous experimental protocols allowing assessing these traits are already well established and have successively been used many times [27-30], what may permit comparisons with effects of other previously examined factors.

\section{Material and methods}

\section{Collection and maintenance of ants}

The experiments were made on two colonies of M. sabuleti collected in June 2018, in an abandoned quarry located at Marchin (Belgium). Each colony was maintained, as usual [27-30], in two glass tubes half filled with water, a cotton plug separating the ants from the water, and these nest tubes were deposited in a tray $(34 \times 23 \times 4 \mathrm{~cm})$. The ants were fed with pieces of Tenebrio molitor larvae (Linnaeus, 1758) delivered three times per week, and with sugar water permanently provided in cotton plugged tubes. The ants of the same colony are here often named 'nestmates'. The ambient temperature was $c a 20^{\circ} \mathrm{C}$, the humidity $80 \%$, the lighting 330 lux, and the electromagnetism surrounding field 2 $\mu \mathrm{Wm}^{2}$, all this being optimum for the species. The acoustic baseline was measured thanks to a professional sound level meter data logger (Velleman'-DEM202). Its median (and quartiles) equaled 40.0 (39.041.0) decibels; its mean (and standard deviation) equaled 40.4 (1.3) decibels.

\section{Artificial environmental parameters used}

Two different beats of a metronome, 42 beats per minute (BPM) and $200 \mathrm{BPM}$, were successively used for each examined ants' trait, after the corresponding control experiment was made (Figure 1A). In other words, for each examined trait, the control experiment was made, then the metronome was switched on and the same trait was again assessed first under 42 BPM, secondly under 200 BPM. The amount of decibels assessed using the sound level meter had a median (and quartiles) values of 42.0 (38.7-47.0) decibels and a mean (and standard deviation) values of 42.2 (4.3) decibels for $42 \mathrm{BPM}$, as well as a median (and quartiles) values of 69.0 (69.0-69.0) decibels and a mean (and standard deviation) values of $69.9(0.2)$ decibels for 200 BPM. The later noise was thus more uniform than the former one. In the same way, for each examined ants' trait, a control experiment was made, then the noise of flowing water was created (Figure 2A), and the same trait was again assessed under that flowing water noise. The number of decibels assessed using the sound level meter had a median (and quartiles) values of 54.0 (53.0-54.0) decibels and a mean (and standard deviation) values of 53.7 (1.0) decibels. It was thus rather uniform (less than the 42 BPM noise but more than the 200 BPM noise) and had an intensity intermediate between those of the beats.

\section{Ants' physiological and ethological traits examined}

Linear and angular speeds, orientation to an alarm signal: These traits were assessed on ants walking in their tray, the speeds without stimulating the ants, the orientation by stimulating them with a nestmate tied to a piece of white paper (Figures $1 \mathrm{~B} 1$ and 2B2). A tied nestmate emits its mandibular glands attractive pheromone. As in previous works [27-30], for the ants' speeds as well as for their orientation, the trajectory of 40 workers was recorded and analyzed thanks to appropriate software [31]. The linear speed (in $\mathrm{mm} / \mathrm{s}$ ) is the length of a trajectory divided by the time spent to travel it. The angular speed (in angular degree $/ \mathrm{cm}=$ ang. $\mathrm{deg} / \mathrm{cm}$ ) is the sum of the angles made by successive adjacent segments, divided by the length of the trajectory. The orientation (in ang. deg.) towards a given location is the sum of the successive angles made by the direction of the trajectory and that towards the location, divided by the number of measured angles. When the value of orientation is lower than $90^{\circ}$, the animal has a tendency to orient itself towards the location; when it is larger than $90^{\circ}$, the animal has a tendency to avoid the location. The median and quartiles of each distribution of 40 values were established.

Audacity: As in previous works [27-30], a tower attached to a platform, both made of strong white paper (Steinbach', the tower height $=4 \mathrm{~cm}$; the tower diameter $=1.5 \mathrm{~cm}$ ), was deposited in the ants' tray, and those present on it were counted 10 times over $10 \mathrm{~min}$ (Figures 1C1, 1C2, 2C1 and 2C2). The mean and the extremes of the recorded numbers were established, and the numbers obtained for the two colonies as well as over two successive minutes were added for statistical analysis purpose.

Tactile (pain) perception: Ants perceiving the uncomfortable character of a substrate walk on it with difficulties, slowly and sinuously. Individuals which weakly perceive this uncomfortable character, move on a rough substrate more quickly and less sinuously. So, the ants' locomotion on a rough substrate allows evaluating their tactile perception. As in previous works [27-30], a folded piece $(3 \times(2+7+2) 11$ $\mathrm{cm}$ ) of emery paper $\mathrm{n}^{\circ} 280$ paper was tied to the borders and the bottom of a tray $(15 \times 7 \times 4.5 \mathrm{~cm})$, dividing it into a first zone $3 \mathrm{~cm}$ long, a second one $3 \mathrm{~cm}$ long containing the emery paper, and a last one $9 \mathrm{~cm}$ long. Such an apparatus was built for each colony. To make an experiment, 12 ants of each colony were transferred into the first zone of their apparatus, and when they walked on the rough substrate (Figures 1D1, 1D2, 2D1 and 2D2), their linear and angular speeds were assessed as usually (see above).

Brood caring: For each colony, a few larvae and/or nymphs were removed from the nest and set in front of the entrance. Five of these 

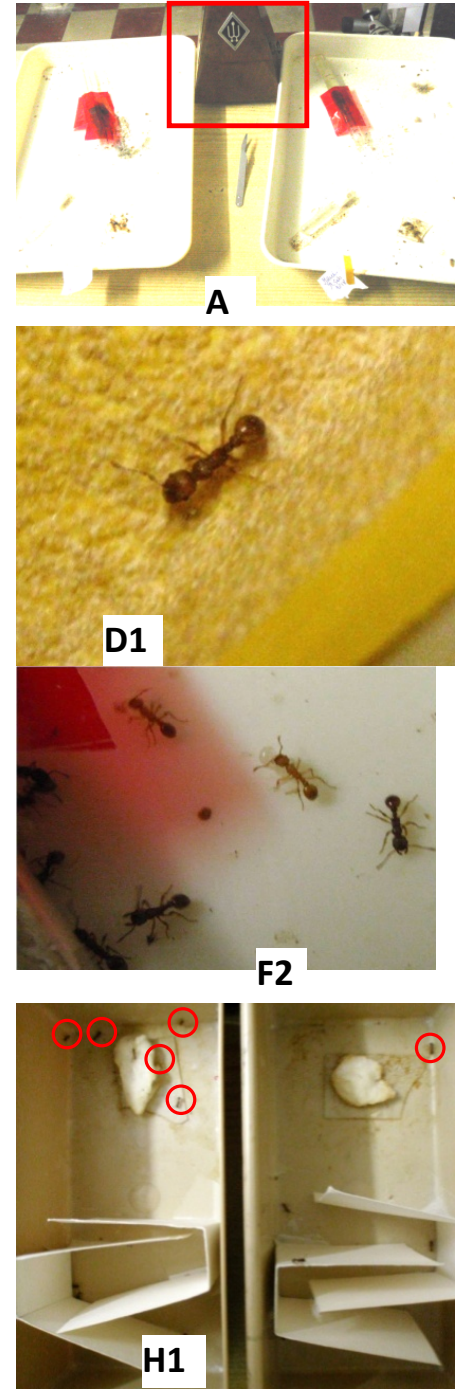
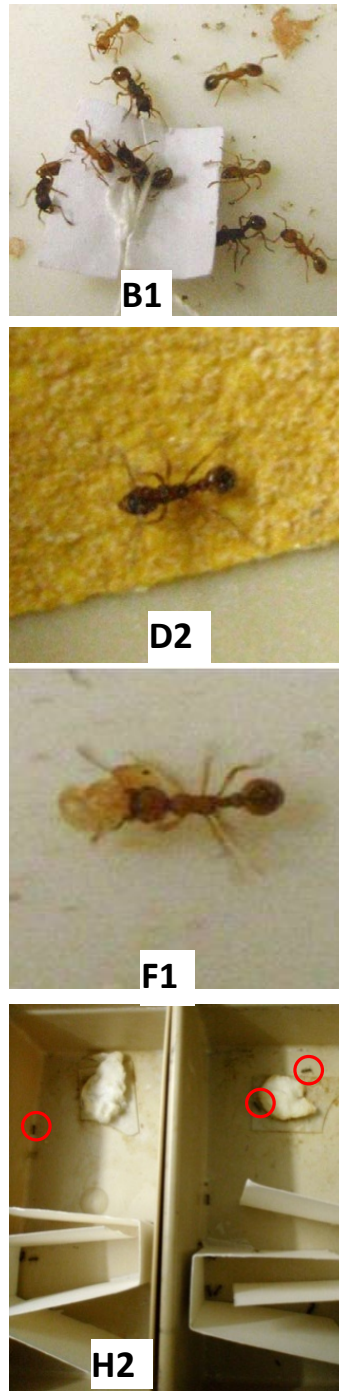
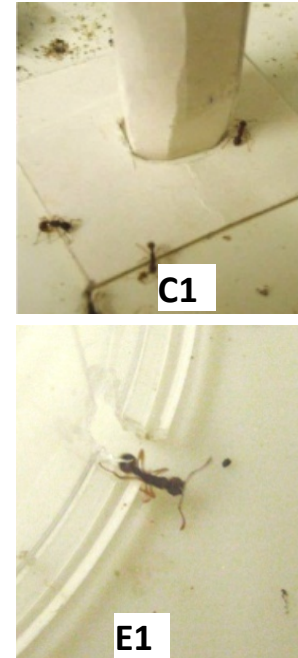

E1

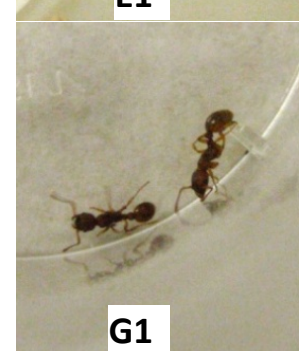

G1

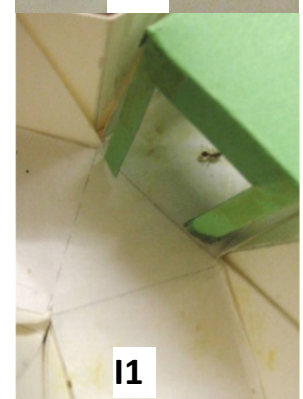

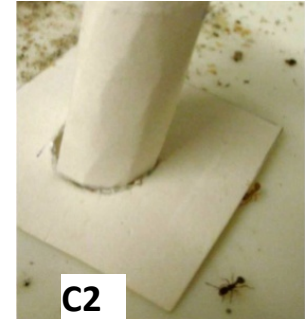
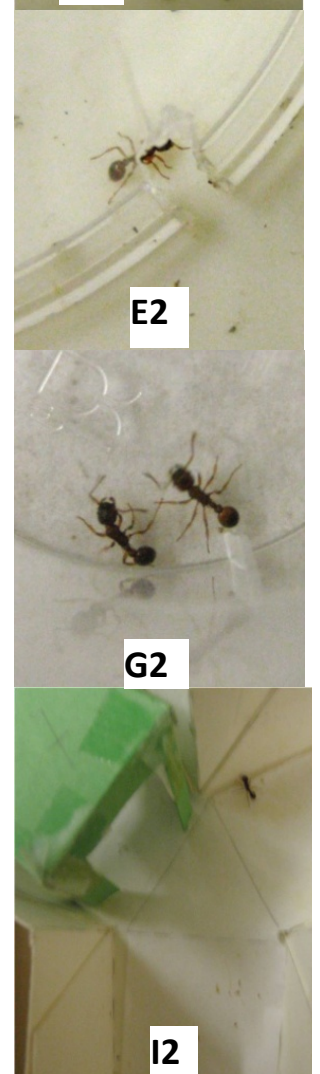

Figure 1. Photos of experiments made on ants under normal environment (1) and under 42 or 200 BPM (2). A: experimental design. Red square $=$ metronome. B: ants having soon reached a tied nestmate emitting its alarm pheromone. C: ants reacting to an unknown risky apparatus. D: ants moving on a rough substrate very well (2) but poorly (1) perceiving this uncomfortable character. E: ants in an enclosure provided with a small exit easily (1) but not (2) found. F: ants taking care of nymphs and larvae experimentally removed from the nest, correctly (1) and not correctly (2) re-entering them. G: two nesmates not at all (1) and somewhat (2) presenting aggressiveness to one another. $\mathbf{H}$ : ants obliged to cross a path with twists and turns for reaching a large area provided with wet cotton, six (1) and three (2) having succeeded in doing so. I: ants, conditioned to a hollow green cube, tested in a Y-apparatus provided with this cue, and giving the correct (1) and the wrong (2) response. Red circles: ants

larvae or nymphs, and the ants' behavior towards them, were observed (Figures 1F1, 1F2, 2F1 and 2F2) and the larvae or nymphs among these $5+5=10$ observed which were still not replaced in the nest after $5 \mathrm{~s}, 2$, $4,6,8$, and 10 min were counted.

Aggressiveness against nestmates and aliens: As in previous works [27-30], these traits were assessed in the course of five dyadic encounters performed for each colony, using an observed ant and either a nestmate or an alien ant, in a cylindrical cup (diameter $=2 \mathrm{~cm}$, height $=1.6 \mathrm{~cm}$, the borders being covered with talc). Each time, the behavior of the observed ant was characterized by the number of times it did nothing (level 0 of aggressiveness), contacted the opponent with its antennae (level 1), opened its mandibles (level 2), gripped the other ant (level 3 ), tried to sting or stung the opponent (level 4) (Figures 1G1, 1G2, $2 \mathrm{G} 1,2 \mathrm{G} 2,2 \mathrm{G}^{\prime} 1$ and $2 \mathrm{G}^{\prime} 2$ ). The numbers obtained for the two colonies were added. Also, as in previous works [30], the ants' aggressiveness was assessed by the variable "a"=number of aggressiveness levels $2+3$ +4 /number of levels $0+1$.
Escaping behavior: As in previous works [27-30], for each colony, 6 ants were enclosed under a reversed polyacetate glass $(\mathrm{h}=8 \mathrm{~cm}$, bottom diameter $=7 \mathrm{~cm}$, ceiling diameter $=5 \mathrm{~cm})$ set in the ants' tray. A notch $(3$ $\mathrm{mm}$ height, $2 \mathrm{~mm}$ broad) had been made in the rim of the glass bottom to allow the ants escaping (Figures 1E1, 1E2, 2E1 and 2E2). Then, after $30 \mathrm{~s}, 2,4,6,8,10$ and $12 \mathrm{~min}$, the escaped ants and those still enclosed were counted. The results obtained for the two colonies were added, and the ants' ability in escaping was also quantified by the variable ' $n$ ' of ants escaped after $12 \mathrm{~min} / 12$ '.

Cognition: This trait was assessed for the first time when studying the effects of nicotine [32]. In the present work, for each colony, two pieces of white paper (Steinbach, $12 \times 4.5 \mathrm{~cm}$ ) duly folded were again inserted in a tray $(15 \times 7 \times 4.5 \mathrm{~cm})$, dividing so this tray into a first small loggia, then a path with twists and turns, and finally a large loggia containing a piece of wet cotton (Figures $1 \mathrm{H} 1,1 \mathrm{H} 2,2 \mathrm{H} 1$ and $2 \mathrm{H} 2$ ). For making an experiment, 15 ants of each colony were transferred into the first loggia of their apparatus, and those present in this loggia and in the 

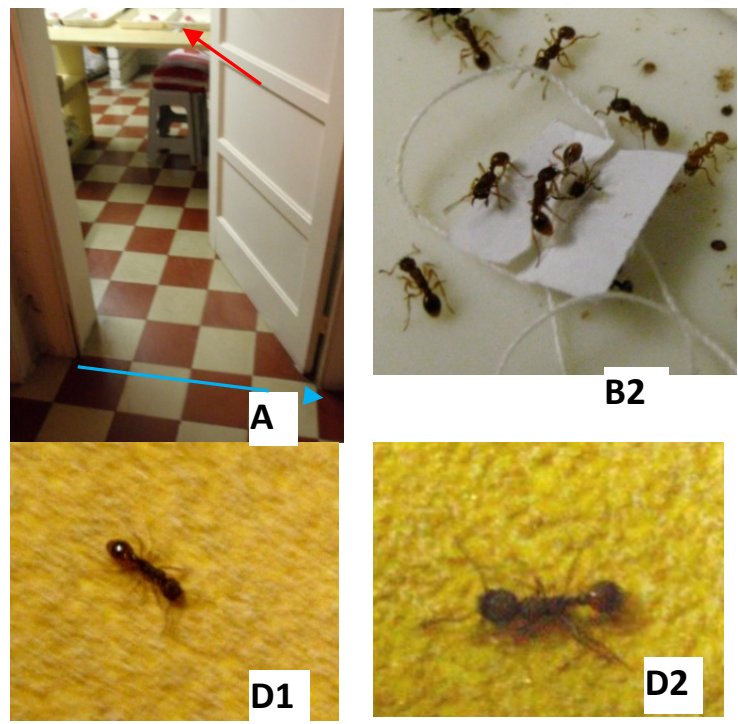

B2
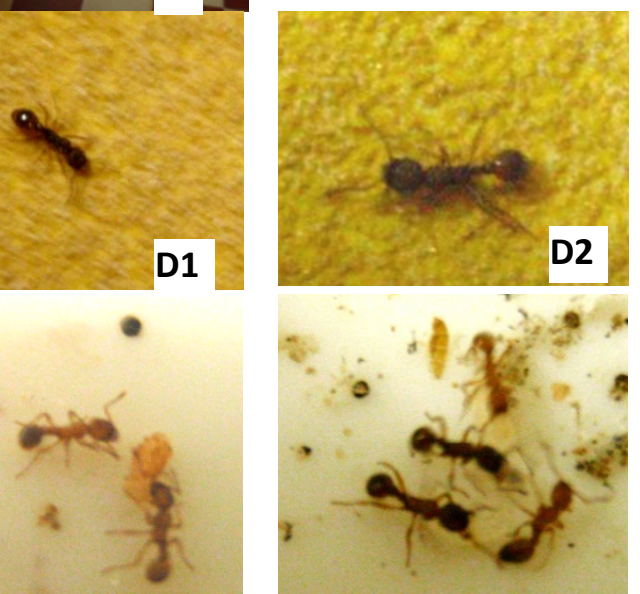

F1

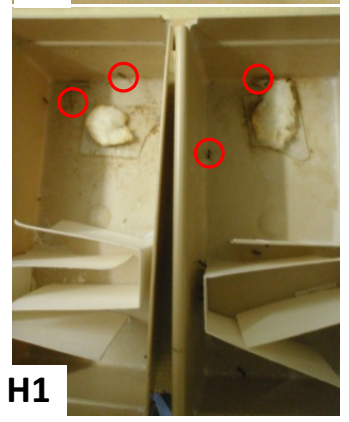

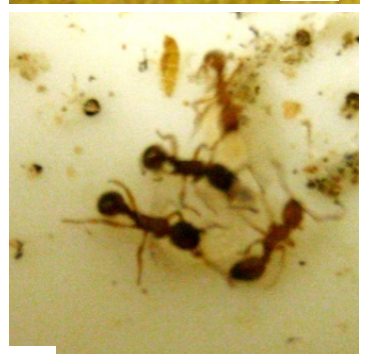

F2

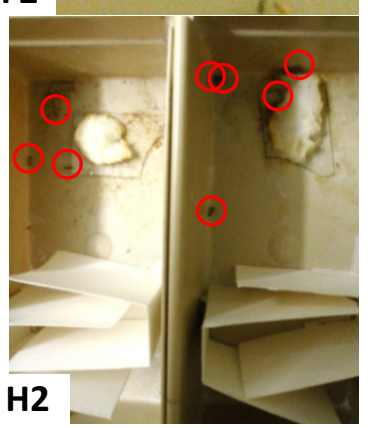

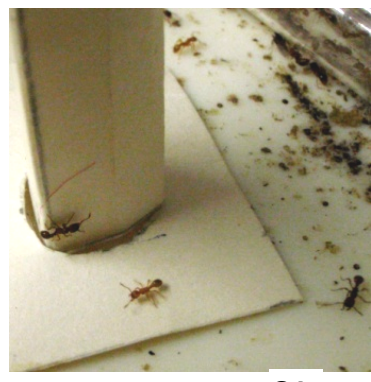

C1
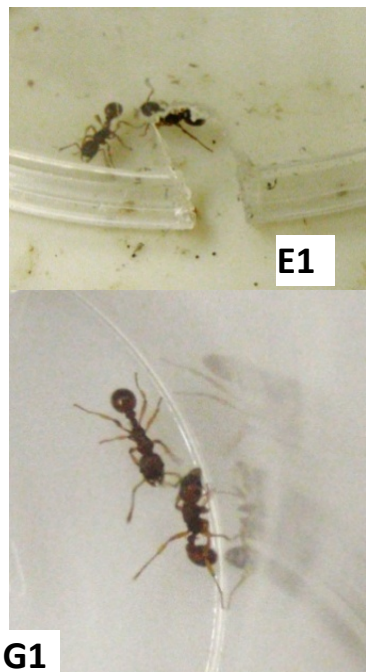

G1

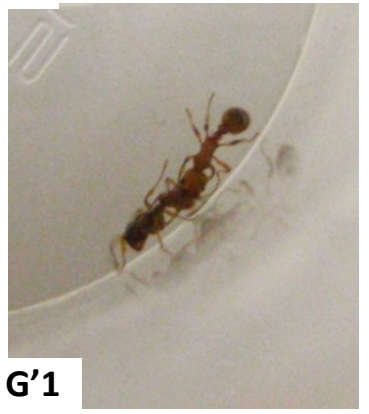

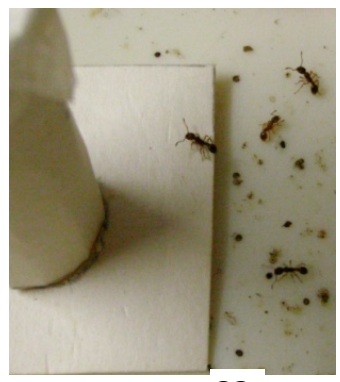

C2

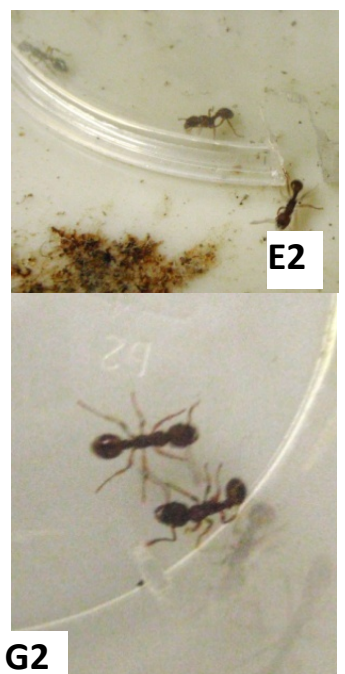

G2

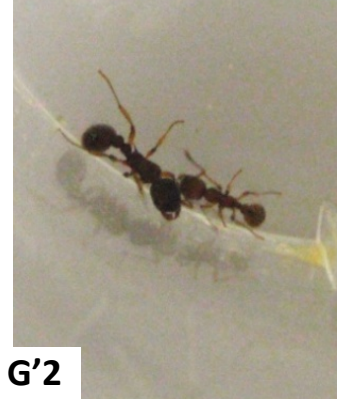

Figure 2. Photos of experiments made on ants under no noise situation (1) and under flowing water noise (2). A: experimental design: red arrow: experimental colonies; dotted blue line: water flowing underground (not visible). B: many ants having very soon reached a tied nestmate emitting its alarm pheromone. C: ants coming onto an unknown risky apparatus. D: ants moving with difficulties on a rough substrate. $\mathbf{E}$ : ants in an enclosure sooner escaping under flowing water noise (2) than under no noise (1). F: ants correctly taking care of nymphs and larvae experimentally removed from the nest. G: two nesmates staying aside without aggressiveness. G': ants aggressing an alien. H: ants having to cross a path with twists and turns for reaching a large area, four (1) and eight (2) having succeeded in doing so; red circles: ants

large one were counted after $30 \mathrm{~s}, 2,4,6,8,10$ and $12 \mathrm{~min}$. The numbers obtained for the two colonies were added.

Memory: First, under control conditions, a green hollow cube was set above the entrance of the sugar water tube of the two colonies, and the ants went so through visual conditioning. Their acquisition of such a conditioning was checked by making tests over time until their conditioning scores no longer increased. To make a test, 10 ants of colony A and of colony B were individually transferred into the entrance of a Y-apparatus provided with a green hollow cube in one of its branches. The Y-apparatus was made of strong white paper and was deposited in a tray $(30 \times 15 \times 4 \mathrm{~cm})$. The green cube was randomly located in the right or the left branch of this Y-apparatus. Moving into the branch containing the cue was considered as giving the correct response (Figures $1 \mathrm{I} 1$ and 1I2). Each test provided the response of 20 ants, and from them, the proportion of correct responses. After the ants were duly conditioned, identical tests were made under the added environmental parameters (i.e. 42 BPM then 200 BPM during a first series of experiments, flowing water noise during a second series). The proportions of correct responses were again, each time, obtained.

\section{Statistical analysis}

The data about ants' linear speed, angular speed, orientation, tactile perception, aggressiveness against nestmates and against aliens, as well as memory were converted into frequencies or ranks. The statistical comparison between the control condition and that with an added environmental parameter was made using the non-parametric $\chi^{2}$ test [33]. Concerning the ants' audacity, brood caring, escape behavior and cognition, the statistical analysis of the comparison was made using the non-parametric test of Wilcoxon [33]. 


\section{Results}

\section{Impact of beats}

Locomotion: The ants' locomotion was impacted by $42 \mathrm{BPM}$ as well as by 200 BPM (Table 1). The linear speed was lower than the control one, significantly during $42 \mathrm{BPM}\left(\chi^{2}=8.57, \mathrm{df}=2,0.01<\mathrm{P}<0.02\right)$ and highly significantly during $200 \mathrm{BPM}\left(\chi^{2}=57.84, \mathrm{df}=2, \mathrm{P}<0.001\right)$. The difference between the impact caused by 42 and 200 BPM was significant $\left(\chi^{2}=52.27, \mathrm{df}=2, \mathrm{P}<0.01\right)$. The ants' angular speed was higher during beats than during the control, this being highly significant under $42 \mathrm{BPM}\left(\chi^{2}=68.84, \mathrm{df}=1, \mathrm{P}<0.001\right)$ as well as under $200 \mathrm{BPM}$ $\left(\chi^{2}=76.09, \mathrm{df}=1, \mathrm{P}<0.001\right)$, and the difference between the impact of these two kinds of beats was significant $\left(\chi^{2}=12.69, \mathrm{df}=2,0.001<\mathrm{P}<0.01\right)$. In fact, under beats, the ants walked erratically, shortly stopped, turned, and came back on their way. Beats have thus a pronounced effect of the locomotion (so on the physiology and the behavior).

Orientation: This trait was affected by $42 \mathrm{BPM}$ as well as by 200 BPM (Figure 2B) (Table 1). The impact was highly significant for 42 BPM $\left(\chi^{2}=16.28, \mathrm{df}=2, \mathrm{P}<0.001\right)$ and for $200 \mathrm{BPM}\left(\chi^{2}=24.96, \mathrm{df}=2\right.$, $\mathrm{P}<0.001)$, and the difference of impact intensity between these two kinds of beats was significant $\left(\chi^{2}=9.40, \mathrm{df}=2,0.001<\mathrm{P}<0.01\right)$. Such an impact was due to the ants' change of locomotion (see above), as well as to the ants' larger attention to (stimulation by) the beats than to (by) the alarm signal emitted by the tied nestmate.

Audacity: Beats, $42 \mathrm{BMP}$ as well as $200 \mathrm{BPM}$, significantly impacted this ethological trait (Figures $1 \mathrm{C} 1$ and 1C2) (Table 1) (for 42 as well as for $200 \mathrm{BPM}$ : $\mathrm{N}=5, \mathrm{~T}=-15, \mathrm{P}=0.031$ ). The difference between the impact caused by the two kinds of beats was not significant $(\mathrm{N}=5$, $\mathrm{T}=+4.5,-10.5, \mathrm{P}=0.266)$. Under beats, the ants often stopped in front of the unknown apparatus and only seldom moved onto it. They seemed being more affected by the beats than being interested by the presence of an unknown apparatus on their area.

Tactile perception: This physiological trait appeared to be affected by $42 \mathrm{BMP}$ and by $200 \mathrm{BPM}$ (Figures $1 \mathrm{D} 1$ and 1D2) (Table 1). Indeed, the

Table 1. Impact of beat noise on eleven ethological and/or physiological traits. Details and statistics are given in the text. Such a noise impacted all the examined traits except the aggressiveness against aliens, and often, the impact of 200 BPM (beats per minute) was larger than that of 42 BPM

\begin{tabular}{|c|c|c|c|}
\hline Traits & Control 1 & 42 beats/minute & 200 beats/minutes \\
\hline Linear speed $(\mathrm{mm} / \mathrm{sec})$ & $11.0(9.8-12.0)$ & $9.9(8.9-10.7)$ & $6.6(6.1-7.2)$ \\
\hline $\begin{array}{l}\text { Angular speed (ang.deg/ } \\
\mathrm{cm} \text { ) }\end{array}$ & $119(100-128)$ & $195(182-220)$ & $213(201-233)$ \\
\hline Orientation (ang.deg) & $30.9(24.4-39.6)$ & $47.1(37.5-60.0)$ & $62.8(43.6-86.6)$ \\
\hline Audacity $\left(n^{\circ}\right)$ & $1.8[1-3]$ & $0.85[0-2]$ & $0.55[0-2]$ \\
\hline \multicolumn{4}{|l|}{ Tactile perception: } \\
\hline Linear speed & $4.6(3.9-5.7)$ & $5.8(4.7-7.0)$ & $6.5(5.5-7.0)$ \\
\hline Angular speed & $259(240-304)$ & $183(157-213)$ & $158(132-183)$ \\
\hline Brood caring $\left(\mathrm{n}^{\circ} / 10\right)$ & 0 & 6 & 8 \\
\hline \multicolumn{4}{|l|}{ Aggressiveness: } \\
\hline Towards nestmates (a) & 0.13 & 0.73 & 0.87 \\
\hline Towards aliens (a) & 3 & 3.67 & 2.7 \\
\hline Escaping behavior $\left(\mathrm{n}^{\circ} / \mathrm{n}^{\circ}\right)$ & $10 / 12=0.83$ & $5 / 12=0.42$ & $4 / 12=0.33$ \\
\hline Cognition: First area $\left(n^{\circ}\right)$ & 9 & 12 & 12 \\
\hline Last area $\left(\mathrm{n}^{\circ}\right)$ & 5 & 3 & 3 \\
\hline Short term memory & $95 \%$ & $60 \%$ & $40 \%$ \\
\hline
\end{tabular}

mm/sec: Millimeter per second; ang.deg: Angular degree; $\mathbf{c m}$ : Centimeter; $\mathbf{n}^{\circ}:$ Number; $\mathbf{a}$ : Variable assessing the ants' aggressiveness ants' linear speed on a rough substrate was larger than the control one, this being not significant for $42 \mathrm{BPM}\left(\chi^{2}=4.27, \mathrm{df}=2,0.10<\mathrm{P}<0.20\right)$, and significant for $200 \mathrm{BPM}\left(\chi^{2}=10.54, \mathrm{df}=2,0.001<\mathrm{P}<0.01\right)$. Also, the ants' sinuosity was lower than the control one, and this was significant for 42 $\operatorname{BPM}\left(\chi^{2}=25.33, \mathrm{df}=2, \mathrm{P}<0.001\right)$ as well as for $200 \mathrm{BPM}\left(\chi^{2}=28.80, \mathrm{df}=1\right.$, $\mathrm{P}<0.001)$. The difference of the impact on the ants' tactile perception caused by the two kinds of beats was slightly significant (concerning the linear speed: $\chi^{2}=3.02, \mathrm{df}=1,0.05 \sim \mathrm{P}<0.10$; concerning the sinuosity: $\left.\chi^{2}=6.01, \mathrm{df}=2,0.02<\mathrm{P}<0.05\right)$. Beats decreased thus the ants' perception what was in agreement with the results obtained when examining the impact on ants' orientation and audacity (see above). Similarly to what was then observed, in the present experiment, the ants seemed to be more affected by the noise than by the uncomfortable character of the substrate.

Brood caring: Under beats, ants less well re-entered the larvae and nymphs experimentally removed from the nest than when they had to do so without any noise (Figures $1 F 1$ and 1F2) (Table 1). Such a result was significant for $42 \mathrm{BPM}$ as well as for $200 \mathrm{BPM}(\mathrm{N}=5, \mathrm{~T}=+15$, $\mathrm{P}=0.031$ ). A slight difference between the ants' behavior under the two kinds of beats could be observed, but was not significant (N=3, NS). In agreement with previous (here above related) observations, the ants seemed to be too perturbed by the beats for efficiently reacting in front of brood removed from the nest.

Aggressiveness against nestmates: This ethological trait was significantly affected by beats, i.e. ants presented some slight aggressiveness towards nestmates (Figures 1G1 and 1G2) (Table 1) (42 BPM: $\left.\chi^{2}=28.80, \mathrm{df}=1, \mathrm{P}<0.001 ; 200 \mathrm{BPM}: \chi^{2}=30.04, \mathrm{df}=2, \mathrm{P}<0.001\right)$. In fact, under beats, the ants more often opened their mandibles in front of the opponent (control: $14 / 122=11 \%, 42$ beats: $47 / 111=42 \%$, 200 beats: $28 / 61=47 \%)$. The difference between the impact caused by the two kinds of beat was not significant $\left(\chi^{2}=0.36, \mathrm{df}=2,0.80<\mathrm{P}<0.90\right)$. Beats induced thus some aggressiveness between nestmates, affecting thus the social relationships in a negative way.

Aggressiveness against aliens: This ethological trait was not impacted by beats; without noise, ants attacked aliens, under beats, they went on doing so (Table 1). The difference of ants' behavior was not significant between control and $42 \mathrm{BPM}\left(\chi^{2}=0.63, \mathrm{df}=2,0.70<\mathrm{P}<0.80\right)$, control and $200 \mathrm{BPM}\left(\chi^{2}=5.67, \mathrm{df}=2,0.05<\mathrm{P}<0.10\right)$, as well as between 42 and $200 \mathrm{BPM}\left(\chi^{2}=4.86, \mathrm{df}=2,0.05<\mathrm{P}<0.10\right)$.

Escaping behavior: This ethological trait was affected by beats, and was more affected by 200 BPM than by 42 BPM (Figures 1E1 and 1E2) (Table 1). Indeed, under beats, the ants essentially moved erratically all around the entire area of the enclosure, and not exclusively along the rim provided with the exit, this being more pronounced under 200 than under 42 BPM. The ants thus only seldom found the exit, and the difference of ants escaped (or still enclosed) was significant between the control and $42 \mathrm{BPM}$, the control and $200 \mathrm{BPM}$, as well as between 42 and $200 \mathrm{BPM}$ (each time, $\mathrm{N}=6, \mathrm{~T}=-21(+21), \mathrm{P}=0.016)$. The present experiment allowed assessing the enclosed individuals' state of stress and some of their cognition. At this time, we can conclude that beats increased the ants' state of stress, and two following experiments examined if such a noise also affects their cognitive capabilities (see below).

Cognition: This physiological trait was affected by 42 BPM and by 200 BPM (Figures $1 \mathrm{H} 1$ and $1 \mathrm{H} 2$ ) (Table 1). The numbers of ants still present in the small area and of those having reached the large area statistically differed between the control and $42 \mathrm{BPM}(\mathrm{N}=7, \mathrm{~T}=28$, $\mathrm{P}=0.008 ; \mathrm{N}=4, \mathrm{~T}=-10, \mathrm{P}=0.063$ respectively), between the control and 
200 BPM $(\mathrm{N}=7, \mathrm{~T}=28, \mathrm{P}=0.008 ; \mathrm{N}=4, \mathrm{~T}=-10, \mathrm{P}=0.063)$, but did not statistically differed between 42 and $200 \mathrm{BPM}(\mathrm{N}=5, \mathrm{~T}=-2.5,+12.5$, $\mathrm{P}=0.125 ; \mathrm{N}=2$, NS, respectively). Beats reduced thus the ants' ability in finding their way through a twists and turns path, decreasing so some of their cognitive abilities.

Short term memory: This important physiological trait was affected by beats (Figures $1 \mathrm{I} 1$ and $1 \mathrm{I} 2$ ) (Table 1 ). The difference of ants' memory was slightly significant between the control and $42 \mathrm{BPM}\left(\chi^{2}=5.16, \mathrm{df}=1\right.$, $0.02<\mathrm{P}<0.05)$ and highly significant between the control and $200 \mathrm{BPM}$ $\left(\chi^{2}=11.39, \mathrm{df}=1, \mathrm{P}<0.001\right)$, but was not significant between 42 and 200 $\mathrm{BPM}\left(\chi^{2}=0.90, \mathrm{df}=1,0.50<\mathrm{P}<0.70\right)$ maybe due to the smallest size of the sample. Noise such beats decreased thus the ants' ability to memorize elements during a short-lasting time.

\section{Control 1-Control 2 comparison}

Some slight numerical differences appeared between the ants' responses presented in the course of the first control (made for examining the impact of beats) and the second control (made for examining the impact of flowing water sound). This is summarized in Table 2 and is illustrated by the photos ' 1 ' (B to $\mathrm{H}$ ) of the Figures 1 and 2 . In details, the following ants' traits remained unchanged: the orientation $\left(\chi^{2}=4.27, \mathrm{df}=2,0.10<\mathrm{P}<0.20\right)$, audacity $(\mathrm{N}=5, \mathrm{~T}=+9.5,-5.5$, $\mathrm{P}=0.360$ ), tactile perception (linear speed: $\chi^{2}=0.40, \mathrm{df}=2,0.80<\mathrm{P}<0.90$; angular speed: $\left.\chi^{2}=2.02, \mathrm{df}=2,0.30<\mathrm{P}<0.50\right)$, brood caring $(\mathrm{N}=0)$, aggressiveness against aliens $\left(\chi^{2}=1.60, \mathrm{df}=3,0.50<\mathrm{P}<0.70\right)$, as well as conditioning and memory (same values). On the contrary, the following ants' traits somewhat numerically changed: the linear speed $\left(\chi^{2}=6.97, \mathrm{df}=2,0.02<\mathrm{P}<0.05\right)$, angular speed $\left(\chi^{2}=5.94, \mathrm{df}=2, \mathrm{P} \sim 0.05\right)$, aggressiveness against nestmates $\left(\chi^{2}=10.92, \quad \mathrm{df}=2, \quad 0.001<\mathrm{P}<0.01\right.$ : more antennal contacts occurred), escape behavior $(\mathrm{N}=6, \mathrm{~T}=+21$, -21, $\mathrm{P}=0.016$ ), and cognition (small area: $\mathrm{N}=7, \mathrm{~T}=28, \mathrm{P}=0.008$; large area: $\mathrm{N}=4, \mathrm{~T}=10, \mathrm{P}=0.063$ ). Such changes are most likely due to the demographical evolution of the colonies' population. The callows, emerged in spring, began to forage and the behavior of some of them was thus recorded in the course of the second control. Such a demographical evolution cannot be avoided, and control experiments must thus always be done a short time before any experimentation (a precaution we took throughout our experimental work [27-30,32,34]).

Table 2. Impact of flowing water noise on eleven ethological and/or physiological traits. Control 1 and control 2 slightly differed due to the demographic evolution of the ant population. Ants' responses under flowing water noise (column 4) were compared to ants' responses during control 2 (column 3). Under flowing water noise, the ants moved slower (more calmly), still less aggressed their nestmates, and could better escape from an enclosure. All the cognitive abilities, ethological and physiological examined traits were thus either unchanged or improved

\begin{tabular}{|l|c|c|c|}
\hline Traits & Control 1 & Control 2 & Flowing water \\
\hline Linear speed (mm/sec) & $11.0(9.8-12.0)$ & $10.0(9.2-11.0)$ & $8.9(7.7-9.7)$ \\
\hline Angular speed (ang.deg/cm) & $119(100-128)$ & $122(86-140)$ & $115(103-131)$ \\
\hline Orientation (ang.deg) & $30.9(24.4-39.6)$ & $39.3(28.0-62.8)$ & $36.0(27.8-56.1)$ \\
\hline Audacity $\left(\mathrm{n}^{\circ}\right)$ & $1.8[1-3]$ & $1.90[1-3]$ & $2.05[1-3]$ \\
\hline Tactile perception: & & & \\
Linear speed & $4.6(3.9-5.7)$ & $4.5(3.7-5.6)$ & $4.9(4.2-6.1)$ \\
Angular speed & $259(240-304)$ & $227(209-282)$ & $220(196-262)$ \\
\hline Brood caring $\left(\mathrm{n}^{\circ} / 10\right)$ & 0 & 0 & 0 \\
\hline Aggressiveness: & & & 0.09 \\
Towards nestmates $(\mathrm{a})$ & 0.13 & 0.17 & 3.39 \\
Towards aliens $(\mathrm{a})$ & 3 & 3.61 & $11 / 12=0.92$ \\
\hline Escaping behavior $\left(\mathrm{n}^{\circ} / \mathrm{n}^{\circ}\right)$ & $10 / 12=0.83$ & $8 / 12=0.67$ & 11 \\
\hline Cognition: First area $\left(\mathrm{n}^{\circ}\right)$ & 9 & 12 & $90 \%$ \\
\hline \multicolumn{1}{|c|}{ Last area $\left(\mathrm{n}^{\circ}\right)$} & 5 & 4 & $95 \%$ \\
\hline Short term memory & $95 \%$ & &
\end{tabular}

\section{Impact of flowing water noise}

Locomotion: Under flowing water noise, the ants walked slower $\left(\chi^{2}=8.14, \mathrm{df}=2,0.01<\mathrm{P}<0.02\right)$ and slightly less sinuously $\left(\chi^{2}=4.12, \mathrm{df}=2\right.$, $0.10<\mathrm{P}<0.20)($ Table 2$)$. It was obvious to the observer that the ants moved more "calmly", i.e. more slowly than usual.

Orientation: Under flowing water noise, the ants perfectly oriented themselves towards a tied nestmates (Figures 2B2) (Table 2). They did so "calmly", and their orientation capability did not differ from the control one $\left(\chi^{2}=0.62, \mathrm{df}=2,0.70<\mathrm{P}<0.80\right)$. The "calming" effect of flowing water did not reduce the ants' usual reaction in the presence of their species' alarm signal.

Audacity: Though being calmer, under flowing water noise, the ants went on coming, to some extent, onto an unknown apparatus (Figures 2C1 and 2C2). There was no statistical difference between the control and the flowing water noise situations as for the numbers of ants counted on such an apparatus (Table 2) $(\mathrm{N}=4, \mathrm{~T}=-3,+7, \mathrm{P}=0.313)$.

Tactile perception: It was obvious to the observer that ants experimented under flowing water noise perfectly perceived the uncomfortable character of the rough substrate (Figures 2D1 and 2D2). They did so at least as well as (i.e. very slightly better than) without any noise (Table 2, lines 5, 6; linear speed: $\chi^{2}=3.29, \mathrm{df}=2,0.10<\mathrm{P}<0.20$; angular speed: $\left.\chi^{2}=1.03, \mathrm{df}=2,0.50<\mathrm{P}<0.70\right)$.

Brood caring: Under flowing water noise, the ants re-entered the larvae and the nymphs experimentally removed from the nest exactly as they did in the absence of noise (Figures $2 \mathrm{~F} 1$ and 2F2) (Table 2). There was no difference at all, as for this social behavior, between ants tested under the two kinds of situation $(\mathrm{N}=0, \mathrm{NS})$. Consequently, flowing water noise did not affect the individuals' social relationship, a deduction checked again thanks to the following experiment (see below).

Aggressiveness against nestmates: Unexpectedly, ants tested under flowing water noise presented still less aggressiveness towards nestmates than ants tested without noise (Figures 2G1 and 2G2) (Table 2 ). This difference between ants observed under the two kinds of situation was statistically significant $\left(\chi^{2}=9.98, \mathrm{df}=2,0.001<\mathrm{P}<0.01\right)$. In fact, under flowing water noise, ants more often stayed doing nothing (65) and made less antennal contacts $(71)(65 / 71=0.92)$ than ants living without that noise $(27 / 65=0.42)$. As a matter of fact, under flowing water noise, the ants more often calmly stayed aside their nestmates. This noise ameliorated thus somewhat the individuals' social relationship (a deduction in agreement with that of the previous experiment: see above).

Aggressiveness against aliens: Flowing water noise did not impact the ants' aggressiveness against aliens (Figures 2G'1 and 2G'2) (Table 2): the ants went on attacking an alien just like went living under no noise situation. The numbers of levels 0 to 4 behaviors were statistically similar for ants living under no and flowing water noise $\left(\chi^{2}=2.54, \mathrm{df}=3\right.$, $0.30<\mathrm{P}<0.50)$. Consequently, even if being somewhat "calmer", the ants perceiving flowing water noise adequately reacted in the presence of an alien, i.e. a danger, what was in agreement with our results on ants' orientation towards an alarm signal (see above).

Escaping behavior: Ants experimented under flowing water noise moved more slowly in the enclosure, essentially along its rim, and thus more quickly found the exit than ants living without noise (Table 2) (Figures 2E1 and 2E2). This difference of behavior between ants tested under the two kinds of situation was significant $(\mathrm{N}=6, \mathrm{~T}= \pm 21, \mathrm{P}=0.016)$. The experiment entitled 'escape behavior' is devoted to the assessment 
of the individuals' state of stress. The more stressed are the individuals, the less promptly they could find the exit and escape. It could thus be concluded that flowing water noise reduced the ants' state of stress, as did for instance an extract of four plants, Sedinal plus ${ }^{\oplus}$ [34].

Cognition: Under flowing water noise, the ants seemed calmer and better progressed through the twists and turns path than ants tested in the absence of noise (Figures $2 \mathrm{H} 1$ and $2 \mathrm{H} 2$ ) (Table 2). The difference of behavior, during the present experiment, i.e. of cognitive abilities, between ants tested under the two kinds of noise situation (flowing water or no noise) was significant (small area: $\mathrm{N}=7, \mathrm{~T}=-28, \mathrm{P}=0.008$; large area: $\mathrm{N}=3$, NS due to the small size of the sample). Note also that cognitive abilities are generally better when the individuals' state of stress is rather low, and this was the case under flowing water noise (see above).

Short term memory: Under flowing water noise, the ants' response to the visual cue (and thus their short-term memory) was identical to that of ants living under baseline noise level (Table 2). The difference of ants' response between the two kinds of noise situation was not at all significant $\left(\chi^{2}=0\right)$. Consequently, flowing water noise may have a calming effect (see above) but without affecting the individuals' memorizing capability.

\section{Discussion and conclusion}

The slight differences observed between the first and the second controls are most likely due to the demographic evolution of the ant population. The callows emerged in spring progressively became to forage and were thus experimented together with the older foragers. This points out the importance of making controls before any test experiment, a precaution we always took in the course of our studies $[30,34]$.

The analysis of the added environmental noises (i.e. beats and flowing water noise) and the results showed that the nature as well as the intensity of such noises accounted for their impact on the ants' physiology and ethology: flowing water noise had beneficial effects, beats had harmful ones; 200 BPM had stronger harmful effects than $42 \mathrm{BPM}$.

We did not examine the impact of beats and of flowing water noise on the ants' long-term memory because this would have lasted for a longer time period (a few days to a few weeks). For such longer-term studies, we should have used new colonies, and should have taken into account the potential confounding factor of the demographic evolution of the colonies as well as the potential harmful cumulative effects of beats noise. Waste of large amounts of water could also be a concern in the case of a longer study. Considering our results, ants seems thus somewhat influenced by artificially produced beats and by environmental water noise, the former seeming to produce negative effects on ants' behaviors and the later to produce beneficial ones. Let us recall that ants play an important role in a large variety of ecosystem [14]. Moreover, ants are largely present in environments transformed by humans, like cities or industrial landscapes and can thus be exposed to artificial sounds and vibrations of high intensities. Therefore, it is plausible that artificially produced sounds (or more generally speaking, vibrations) could generate harmful effects on ant's colonies activities, and maybe causing trophic cascades as illustrated by Barton and coauthors [13].

Of course, insects other than ants can be influenced by noise. Let us cite the works compiled by Hedwig [35], the recent experimental study of Brandon et al. [13] (and references therein), Lee et al. [36] and
Costello et al. [6], among others. Living organisms other than insects can also be impacted by environmental noise. Numerous examples exist: e.g. plants [7], fishes [37], birds [5], and marine mammals [38] among others. Dogs and cats can nowadays be calmed thanks to recorded natural calming noise [39]. Such an effect of music is also valid for other mammals, i.e. for rats [40]. Sounds can also have very harmful effects on vertebrates [41,42] and are used for pest controls in crop management $[43,44]$.

Concerning the humans, they are evidently also affected by environmental noise, frequently while they are performing activities [42,45-48]. Of course, children are also affected by harmful noise [49]. Furthermore, sounds are increasingly used as militarized weapons [50,51] or deterrent devices [52]. Reducing noise pollution, and even using music therapy, is known to be beneficial to the humans' health $[53,54]$. Some kind of noise is nowadays used for avoiding that adolescents and children stay too long time in shops [55].

In conclusion, using ants as models, we found that sounds could affect individuals' physiology and ethology (e.g. the sensitive perception, stress state, social relationship, cognition, and memory), brutal noise doing so adversely, smooth noise doing so beneficially. Such a finding is in accordance with many researchers' results, these researchers working on plants, insects, fishes, birds, mammals or humans. We pledge for more researches on the potential adverse effects of artificially produced high levels of noises/vibrations on the insects communities in urban environment. Ants could be valuable model organisms for such an investigation.

As artificial sound is also well-know to produce harmful effects on peoples, we can thus advise, for humans including the children, to avoid or at least minimize the exposition to brutal, perturbing noise, and to add, as possible or necessary, some natural or manmade smooth, calming noise in the individuals' environment.

Other environmental factors can also influence the individuals' physiology and ethology (see the introduction section, [56]). In two future works, we shall examine the impact of odors and of continuous lighting exposure.

\section{Conflicts of interest}

We affirm having no conflict of interest as for the use of any noise for any animals' or humans' therapy. We work only on ants and receive no money for making our research.

\section{Acknowledgement}

We are very grateful to Roger Cammaerts who helped us to collect ants, to measure the produced artificial noise, and to finish the paper in due time.

\section{References}

1. Goudie AS (2018) Human impact on the natural environment - past, present and future (8th edition), University of Oxford, Wiley Blackwell.

2. Barber JR, Crooks KR, Fristrup KM (2010) The costs of chronic noise exposure for terrestrial organisms. Trends Ecol Evol 25: 180-189. [Crossref]

3. Bradbury JW, Vehrencamp SL (1998) Principles of animal communication. Sinauer Associates, Inc, Publishers, Sunderland, Massachusetts.

4. Buxton RT, McKenna MF, Mennitt D, Fristrup K, Crooks K, et al. (2017) Noise pollution is pervasive in U.S. protected areas. Science 356: 531-533. [Crossref]

5. Francis CD, Ortega CP, Cruz A (2009) Noise pollution changes avian communities and species interactions. Curr Biol 19: 1415-1419.

6. Costello RA, Symes LB (2014) Effects of anthropogenic noise on male signaling behavior and female phonotaxis in Oecanthus tree crickets. Animal Behaviour 95: 15-22. 
7. Collins ME, Foreman JE (2001) The effect of sound on the growth of plants. Canadian Acoustics 29: 3-8.

8. Luo J, Siemers BM, Koselj K (2015) How anthropogenic noise affects foraging. Glob Chang Biol 21: 3278-3289. [Crossref]

9. McMahon TA, Rohr JR, Bernal XE (2017) Light and noise pollution interact to disrupt interspecific interactions. Ecology 98: 1290-1299.

10. Orci KM, Petróczki K, Barta Z (2016) Instantaneous song modification in response to fluctuating traffic noise in the tree cricket Oecanthus pellucens. Animal Behaviour 112: $187-194$

11. Schmidt R, Morrison A, Kunc HP (2014) Sexy voices-no choices: Male song in noise fails to attract females. Animal Behaviour 94: 55-59.

12. Morley EL, Jones G, Radford AN (2013) The importance of invertebrates when considering the impacts of anthropogenic noise. Proc Biol Sci 281: 20132683. [Crossref]

13. Barton BT, Hodge ME, Speights CJ, Autrey AM, Lashley MA, et al. (2018) Testing the AC/DC hypothesis: Rock and roll is noise pollution and weakens a trophic cascade. Ecol Evol 8: 7649-7656. [Crossref]

14. Folgarait PJ (1998) Ant biodiversity and its relationship to ecosystem functioning: A review. Biodiversity and Conservation 7: 1221-1244.

15. Passera L, Aron S (2005) Les fourmis: Comportement, organisation sociale et évolution. Les Presses Scientifiques du CNRC, Ottawa, Canada, pp: 480.

16. Sherwood L, Klandorf H, Yancey P (2016) Physiologie animale. De Boeck superieur Editors, Belgium, pp: 904

17. Bousquet C (2003) Bêtes de science. Seuil, pp: 240.

18. Andre RG, Wirtz RA, Das YT (1989) Insect Models for Biomedical Research. In: Woodhead AD, editor. Non mammalian Animal Models for Biomedical Research. CRC Press, Boca Raton, FL, pp: 62-70.

19. Abramson CI, Wells H, Janko B (2007) A social insect model for the study of ethanol induced behavior: The honey bee. In Yoshida R (Ed.), Trends in Alcohol Abuse and Alcoholism Research. Nova Sciences Publishers, Inc., pp: 197-218.

20. Cammaerts MC (2018) Physical dependence on a substance occurs when the effect of this substance rapidly decreases after withdrawal. JSM Anat Physiol 3: 1017.

21. Hölldobler B, Wilson EO (1990) The ants. Harvard University Press, Springer-Verlag: Berlin, pp: 32 .

22. Billen J, Morgan ED (1998) Pheromone communication in social insects - sources and secretions. In: Vander Meer RK, Breed MD, Espelie KE, Winston MLK (editors.), Pheromone Communication in Social Insects: Ants, Wasps, Bees, and Termites; Westview Press: Boulder, pp: 3-33

23. Cammaerts MC, Cammaerts D (2014) Comparative outlook over three Myrmica species' biotopes and foragers' know-how. Biologia 69: 1051-1058.

24. Cammaerts MC, Cammaerts R (2015) Ontogenesis of ants' cognitive abilities (Hymenoptera, Formicidae). Adv Stud Biol 7: 335-350.

25. Cammaerts MC, De Doncker P, Patris X, Bellens F, Rachidi Z, et al. (2012) GSM $900 \mathrm{MHz}$ radiation inhibits ants' association between food sites and encountered cues. Electromagn Biol Med 31: 151-165. [Crossref]

26. Cammaerts MC, Rachidi Z, Bellens F, De Doncker P (2013) Food collection and responses to pheromones in an ant species exposed to electromagnetic radiation. Electrom Biol Med 33: 282-288.

27. Cammaerts MC, Cammaerts D (2015) Physiological and ethological effects of fluoxetine, on ants used as biological models. Int J Biol 7: 1-18.

28. Cammaerts MC, Cammaerts R (2018) Ethological and physiological effects of the recently most used analgesic, ibuprofen; A study on ants as models. EC Pharmacol Toxicol 6: 251-267.

29. Cammaerts MC (2017) Physiological and Ethological Effects of Glutathione, a Powerful Antioxidant Food Complement; A Study on Ants as Models. MOJ Biol Med 2: 00045 .

30. Cammaerts M-C, Cammaerts R (2018) Safety of glucosamine, examined on ants as models. MOJ Biol Med 3: 132-142.

31. Cammaerts MC, Morel F, Martino F, Warzée N (2012) An easy and cheap softwarebased method to assess two-dimensional trajectories parameters. Belg J Zool 142: 145151.
32. Cammaerts MC, Gosset G, Rachidi Z (2014) Some physiological and ethological effects of nicotine; studies on the ant Myrmica sabuleti as a biological model. Int $J$ Biol 6: 64-81.

33. Siegel S, Castellan NJ (1989) Non-parametric statistics for the behavioural sciences; McGraw-Hill Book Company: Singapore, pp: 396.

34. Cammaerts MC, Cammaerts R, Rachidi Z (2016) Effects of four plants extract used as an anxiolytic - A study on ants as models. Adv Biomed Pharm 3: 280-295.

35. Hedwig B (2014) Signals and Communication. Ed. Hedwig B, Ed. Series Janik VM, McGregor P, Springer-Verlag Berlin Heidelberg.

36. Lee Y, Kim H, Kang TJ, Jang Y (2012) Stress response to acoustic stimuli in an aphid: A behavioral bioassay model. Entomol Res 42: 320-329.

37. Simpson SD, Radford AN, Nedelec SL, Ferrari MC, Chivers DP, et al. (2016) Anthropogenic noise increases fish mortality by predation. Nat Commun 7: 10544. [Crossref]

38. Richardson WJ, Greene CR, Malme CI, Thomson DH (2013) Marine Mammals and Noise. Academic Press, San Diego, London.

39. Bowman A, Scottish S, Dowell FJ, Evans NP (2015) 'Four Seasons' in an animal rescue centre; classical music reduces environmental stress in kenneled dogs. Physiol Beh 143: 70-82.

40. Niehues da Crehuz J, Delwing de Lima D (2011) The power of classic music to reduce anxiety in rats treated with simvastatin. Basic and Clinical bcn ium 2: 5-11.

41. Moxon R, Allison A, England GCW (2010) Effect of ultrasonic devices on the distraction behavior of guide dogs. Int J Orient Mobil 3: 27-31

42. Passchier-vermeer W, Passchier WF (2000) Noise exposure and public health. Environ Health Perspect 108: 123-131.

43. Frings H (1964) Sound in vertebrate pest control. Proceed 2nd Vert. Pest Control Conf, ppA: 49-56.

44. Bomford M, O'Brien PH (1990) Sonic deterrents in animal damage control: A review of device tests and effectiveness. Wildi Soc Bull 18: 411-422.

45. Atmaca E, Peker I, Altin A (2005) Industrial Noise and Its Effects on Humans. Pol J Environ Stud 14: 721-726.

46. Pedersen E (2009) Effects of wind turbine noise on humans. Meeting on Wind Turbine Noise, Aalborg Denmark.

47. Pirrera S, De Valck E, Cluydts R (2010) Nocturnal road traffic noise: A review on its assessment and consequences on sleep and health. Environ Int 36: 492-498. [Crossref]

48. Stansfeld S, Haines M, Brown B (2000) Noise and health in the urban environment. Rev Environ Health 15: 43-82. [Crossref]

49. Bistrup ML, Hygge S, Keiding L (2001) Health effects of noise on children and perception of the risk of noise. National Institute of Health, Denmark.

50. https://www.cjc-online.ca/index.php/journal/article/view/2261

51. http://www.article11.info/?Le-son-comme-arme-3-4-les-hautes

52. Akiya M (2010) Silent Alarm: The mosquito youth deterrent and the politics of frequency. Can J Commun 35: 455-471.

53. Cabrera IN, Lee MHM (2000) Reducing noise pollution in the hospital setting by establishing a department of sound: A survey of recent research on the effects of noise and music in health care. Preventive Medicine 30: 339-345.

54. Comeaux T, Comeaux T (2013) The effect of complementary music therapy on the patient's postoperative state anxiety, pain control, and environmental noise satisfaction. Medsurg Nurs 22: 313-318. [Crossref]

55. https://www.01net.com/actualites/on-a-teste-le-boitier-anti-jeunes-377460.html

56. Castelhano-Carlos MJ, Baumans V (2009) The impact of light, noise, cage cleaning and in-house transport on welfare and stress of laboratory rats. Lab Anim 43: 311-327. [Crossref]

Copyright: (C)2018 Cammaerts M. This is an open-access article distributed under the terms of the Creative Commons Attribution License, which permits unrestricted use, distribution, and reproduction in any medium, provided the original author and source are credited. 